\title{
Electronic Health Records Access During a Disaster
}

\author{
Kevin Horahan ${ }^{1}$, Herman Morchel ${ }^{2}$, Murad Raheem ${ }^{3}$, Lee Stevens ${ }^{4}$
}

1. U.S. Department of Health and Human Services, Office of the Assistant Secretary for Preparedness and Response, Office of Policy and Planning, Division of Health System Policy

2. Emergency Trauma Department, Hackensack University Medical Center, Steven J. Pawlak MSM, MICP, NJ EMS Task Force

3. U.S. Department of Health and Human Services, Office of the Assistant Secretary for Preparedness and Response, Office of Preparedness and Emergency Operations, Regional Emergency Coordinator Program

4. U.S. Department of Health and Human Services, Office of the National Coordinator for Health Information Technology

\begin{abstract}
As has been demonstrated previously, medical care providers that employ an electronic health records (EHR) system provide more appropriate, cost effective care. Those providers are also better positioned than those who rely on paper records to recover if their facility is damaged as a result of severe storms, fires, or other events. The events surrounding Superstorm Sandy in $\mathbf{2 0 1 2}$ made it apparent that, with relatively little additional effort and investment, health care providers with EHR systems may be able to use those systems for patient care purposes even during disasters that result in damage to buildings and facilities, widespread power outages, or both.

Correspondence: Kevin.horahan@hhs.gov

DOI: $10.5210 /$ ojphi.v5i3.4826

Copyright @2014 the author(s)

This is an Open Access article. Authors own copyright of their articles appearing in the Online Journal of Public Health Informatics. Readers may copy articles without permission of the copyright owner(s), as long as the author and OJPHI are acknowledged in the copy and the copy is used for educational, not-for-profit purposes.
\end{abstract}

\section{Introduction}

There are numerous practical reasons for implementing an electronic health records (EHR) system and a growing body of evidence in the literature suggesting that there are clinical and financial benefits of using EHRs in the ordinary course of providing care. ${ }^{1}$ It stands to reason that clinicians and their patients might enjoy similar benefits in extraordinary situations - such as during a declared disaster or other public health emergency.2 This article describes the situation at the Long Beach Medical Center (New York) in the immediate aftermath of Hurricane Sandy in 2012 and how its EHR system was made available despite the facility itself having been rendered inoperable for patient care. 


\section{Background}

The National Planning Frameworks (the Frameworks) address the five mission areas of preparedness - prevention, protection, mitigation, response, and recovery. 2 The Frameworks focus on a "whole community" concept, a shared responsibility model where people, businesses, other groups, and government (at all levels) work together to achieve the National Preparedness Goal. ${ }^{2}$

One of the basic tenets of preparedness is, to the greatest extent possible, to incorporate into everyday operations those systems, processes, equipment, and strategies that might be employed during a disaster. ${ }^{3}$ Familiarity with those elements that may be employed during a large scale event eliminates one potential stumbling point. The daily use of an EHR system is an excellent example.

The development and "meaningful use" of accessible, secure, and interoperable EHR systems and, ultimately, the creation of nationwide interoperable health information exchange capacity is part of the Federal Health Information Technology Strategic Plan. ${ }^{4}$ Likewise, strategic objective number four of the National Health Security Strategy identifies "the use of portable, standardsbased, interoperable EHRs" as an essential element of a "prepared and responsive health system". 5 The everyday use of health information technology (HIT) can speed up the diagnosis of problems, help coordinate care, reduce duplicative treatments, limit the risk of medication interactions, and ultimately lower health care costs. ${ }^{1}$ Accordingly, maintaining the HIT infrastructure during a disaster or other large scale event may be one way to reduce stress on the health care system which could, ultimately, make it more resilient.

In the fall of 2012, nearly eight years after Hurricane Katrina, the HIT infrastructure was tested when a hurricane with even larger breadth than Katrina roared up the Eastern seaboard, pummeled the New Jersey coastline, and sent a wall of water toward the most densely populated city in the United States. ${ }^{6}$ Hurricane Sandy caused 147 deaths and nearly $\$ 50$ billion in damage. ${ }^{6}$ Recovering from Sandy's devastation is ongoing and will continue for years to come.

With more than a decade of planning since the attacks of September 11, 2001, New York State has invested deeply in the development of health information exchange. With additional support from the Health Information Technology for Economic and Clinical Health (HITECH) Act, ${ }^{7}$ the State has moved closer to the realization of the State Health Information Network - New York (SHINNY). ${ }^{8}$ While water was impossible to hold back, the availability of health information before, during, and after the storm remained remarkably stable. Among the users of EHRs in the greater New York City area there was only one report of records being lost, in a small clinic that was actually in the process of converting their paper records into an EHR system. ${ }^{9}$ However, there were widespread reports of paper records being lost. ${ }^{9}$

In New Jersey, with fewer hospitals in the direct impact zone, the State Regional Extension Center Program planned in advance by contacting providers prior to the storm's landfall with instructions on how to back up data stored in the their EHRs. This planning assured that patient information would be safe and accessible during and after the storm. 


\section{Discussion}

\section{Hurricane Sandy's Impact on Long Beach Medical Center}

Long Beach Medical Center (LBMC) is located east of New York City on Long Beach Barrier Island, immediately adjacent to Reynolds Channel. The facility has a 162 bed acute care hospital as well as a 200 bed skilled nursing facility specializing in rehabilitation. ${ }^{10}$ LMBC handles over 13,000 emergency department visits in a typical year and the facility has had an emergency department EHR system in place since 2009 (C.C., written communication, March 2013).[REMOVED HYPERLINK FIELD]

During Hurricane Sandy, LBMC was taken completely offline by the storm surge. Its basement, which houses the heating, electrical, fire alarm, and communications systems as well as the food and laundry services, was flooded with more than ten feet of water. ${ }^{11}$ In an effort to provide the residents of Long Beach with nearby access to emergency care, the State of New York requested assistance through the Emergency Management Assistance Compact (EMAC). ${ }^{12}$

Shortly after Sandy's landfall, the U.S. Department of Health and Human Services' Office of the Assistant Secretary for Preparedness and Response (ASPR) activated the National Disaster Medical System ${ }^{13}$ at the request of the New York State Department of Health (NYSDOH) and Nassau County Department of Health. Working with their state and local partners, ASPR personnel established a Disaster Medical Assistance Team (DMAT) Base of Operations at a soccer field a short distance from LBMC. This DMAT allowed the Long Beach community to receive emergency care without having to leave the immediate area. This also reduced the number of patients seeking treatment at already overburdened facilities in the surrounding communities.

To begin the process of recovery as soon as practical, ASPR staff again worked with the state and local representatives to transition the DMAT operations back to LBMC. Reestablishing operations at the LBMC site, in whatever capacity, would allow their staff - many of whom were furloughed after Sandy - to return to work and bring the community one step closer to full recovery. However, because the LBMC facility itself was inoperable, another option was needed to begin providing medical care.

\section{Mobile Satellite Emergency Department}

In 2006, the Northern New Jersey Urban Areas Security Initiative (UASI) began to develop a resource to help deal with a surge of patients. The intended purpose of the resource was to supplement the assets of the region's emergency care providers - both facility and field based. At about the same time, Hackensack University Medical Center (HUMC) was seeking funds from the Department of Defense with the intention of creating a deployable hospital that would include an emergency room, operating room, and accompanying support facilities. When the two parties learned of each other's projects, they decided to collaborate to create one overall comprehensive program called the MSED or Mobile Satellite Emergency Department. ${ }^{14}$

Shortly after acquiring the MSED, the HUMC staff identified the potential need for a high speed, secure data link to the hospital. Providing services remotely - whether during a disaster or for purposes such as screening or prevention - often has significant benefits. However, having remote 
access to an existing EHR system would allow the MSED staff to view and update existing patient records. Because of this, they researched the cost and feasibility of several data transfer technologies. Testing was conducted on an unlicensed, point to point, microwave Ethernet bridge system with capabilities that included data speeds of up to $300 \mathrm{Mbps}$ over a distance exceeding 100 miles and data security provided by AES 256 encryption. As part of the test, one unit was mounted on the rooftop of HUMC in Hackensack, NJ and the other on a van which was driven to various locations in and around Hackensack. The unit operates most efficiently when in direct line of site; however non-line of site operation is possible albeit with reduced performance. The testing was highly successful and secure data links were established from multiple locations.

The MSED has become the centerpiece of a comprehensive surge capacity project that serves the UASI region and state. This is accomplished through an extensive collaboration process with the NJ Department of Health (NJDOH), the New Jersey EMS Task Force (NJEMSTF), the Medical Reserve Corps (MRC), and various hospital and health care entities. HUMC hosts the MSED assets and provides medical staff to operate within the MSED while the NJEMSTF provides overall command, planning, and logistical support during deployments. Generally, staffing is provided for prolonged operations or deployments through collaborative agreements with the MRC and other hospital entities.

When New York initiated its request for EMAC assistance during Hurricane Sandy, the MSED was among the assets requested. The discussion between representatives of the NYSDOH and the NJDOH that led to the request took place in the Joint Field Office and was facilitated by ASPR Regional Emergency Coordinators. Through a Federal Emergency Management Agency (FEMA) mission assignment, this operation was supported by several ASPR assets.

\section{Use of Innovative Technology}

Health care providers are encouraged to incorporate preparedness into their everyday operations and using an EHR system is a great example. In setting up the MSED at the Long Beach location, discussions with the LBMC providers who would be working in the MSED took place regarding the use of the LBMC EHR and radiology image transfer programs. The advantages, as discussed previously, included staff familiarity, access to existing medical records for the population, archiving of medical information for new encounters in the temporary facility, and transfer of digital radiology images for interpretation by offsite radiologists. Because the LBMC's data center is located approximately one mile away from the main facility on the upper floor of a multi-story commercial office building, the EHR system was safe from the flood waters. Normally, fiber optic data lines are used to link the data center with the hospital building. However, due to physical damage to the hospital infrastructure by flooding and loss of integrity of the fiber optic lines due to downed trees and other debris, the existing connections between the data center and hospital were unusable.

The HUMC MSED team proposed using the microwave link system that they had tested previously to link the LBMC data center with the temporary emergency department being set up in the medical center's parking lot. Because of the experience gained and success of the prior testing the group decided to deploy the system at LBMC; the manufacturer's local engineering representative came to the site and provided technical support. One unit was mounted on the roof of the data center and the other on the roof of the hospital. The units use Power over Ethernet (POE) so a single data line 
is all that was required from the rooftop unit to the MSED and tent structures. Once the cable was brought inside the patient care areas, a router was used to establish a local network and the hospital's computers, displays, and printers were installed. Connection of the MSED digital x-ray system to the network allowed transfer of images to offsite radiologist physicians for interpretation as needed. In short, despite the austere situation, the care provided could still approximate that provided on a 'normal' day.

\section{Conclusion}

The impact of Hurricane Sandy put many aspects of the Frameworks - particularly the Mitigation, Response, and Recovery components - to the test. It also helped to identify where strategies such as employing an EHR system can cross the frameworks from mitigation to response, and into recovery. While some of the events at LBMC were serendipitous, there were a number of areas where preparedness efforts paid off. The implementation and regular use of EHR systems is clearly on that list as is the partnership developed between federal, state, local, and private entities involved in disaster planning. We have seen before, and it was true during Sandy, that the use of an EHR system can facilitate record recovery if a facility is damaged or destroyed. What this experience also shows is that, with only a small amount of additional planning, it is possible to maintain access to an EHR system during a significant event even if a facility has been damaged or destroyed.

\section{Disclaimer:}

The contents of the article represent the personal views of the individual authors and do not necessarily express the opinion or policy of the US Department of Health and Human Services (HHS), Hackensack University Medical Center (HUMC), or the New Jersey EMS Task Force (NJEMSTF). No statement in the articles should be construed as an official position of HHS, HUMC, or NJEMSTF.

\section{Acknowledgments:}

Cheryl Chapman, Peter Genova, and Sharon Player of the Long Beach Medical Center provided information and comments to the authors; and Alicia Livinski from the National Institutes of Health Library assisted with editing and manuscript preparation.

\section{References}

1. Menachemi N, Collum T. 2011. Benefits and drawbacks of electronic health record systems. Risk Manag Healthc Policy. 4, 47-55. PubMed http://dx.doi.org/10.2147/RMHP.S12985

2. U.S. Department of Homeland Security. National planning frameworks. Washington, DC: U.S. Department of Homeland Security; May 2013: http://www.fema.gov/national-planningframeworks. Accessed November 22, 2013.

3. Abir M, Mostashari F, Atwal P, et al. 2012. Electronic health records critical in the aftermath of disasters. Prehosp Disaster Med. 27, 620-22. PubMed

http://dx.doi.org/10.1017/S1049023X12001409 
4. Office of the National Coordinator for Health Information Technology. Federal health information technology strategic plan 2011 - 2015. Washington, DC: Office of the National Coordinator for Health Information Technology:

http://www.healthit.gov/sites/default/files/utility/final-federal-health-it-strategic-plan0911.pdf. Accessed August 9, 2013.

5. U.S. Department of Health and Human Services. National health security strategy of the United States of America. Washington, DC: U.S. Department of Health and Human Services; December 2009:

http://www.phe.gov/Preparedness/planning/authority/nhss/strategy/Documents/nhssfinal.pdf. Accessed August 9, 2013.

6. Blake ES, Kimberlain TB, Berg RJ, et al. Tropical cyclone report - hurricane Sandy (AL182012) 22 - 29 October 2012. Miami, FL: National Hurricane Center, National Weather Service; 12 February 2013: $\quad$ http://www.nhc.noaa.gov/data/tcr/AL182012_Sandy.pdf. Accessed August 9, 2013.

7. Public Law 111-5: Title XIII of Division A of the American Recovery And Reinvestment Act of 2009. (123 Stat. 226; Date: 2/17/09).

8. New York eHealth Collaborative. Statewide health information network for New York. 2012; http://nyehealth.org/what-we-do/statewide-network/. Accessed August 9, 2013.

9. Coughlin B. In the wake of hurricane Sandy: Health IT 1, paper records 0. November 21, 2012; http://www.healthit.gov/buzz-blog/ehr-case-studies/hurricane-sandy-healthinformation-technology/. Accessed August 9, 2013, 2013.

10. Long Beach Medical Center. Who we are. 2012; http://longbeachmedicalcenter.org/WhoWeAre.aspx. Accessed August 9, 2013.

11. NY town eyes hospital reopening months after Sandy. March 23, 2012. http://bigstory.ap.org/article/ny-town-eyes-hospital-reopening-months-after-sandy. Accessed August 9, 2013.

12. National Emergency Management Association. Emergency management assistance compact (EMAC). 2013; http://www.emacweb.org/. Accessed August 9, 2013.

13. Office of the Assistant Secretary for Preparedness and Response. National disaster medical system. http://www.phe.gov/preparedness/responders/ndms/Pages/default.aspx. Accessed August 9, 2013.

14. New Jersey - mobile satellite emergency department (NJ-MSED). 2012; http://www.njmsed.com/. Accessed August 9, 2013. 